and the reception and impact of his ideas in eighteenth-century Europe.

Linnaeus was an avid collector and classifier of 'animals, vegetables and minerals'. He named and described his collections and the many specimens that were returned to Europe from exploration of other parts of the globe. His plant names are the starting point for valid names that follow botanical nomenclature. To be valid, a species name must be attached to one reference or 'type' specimen. This concept was implemented 150 years after Species Plantarum, so - ironically - most of the names assigned by Linnaeus himself do not have clearly associated specimens.

Enter the Linnaean Plant Name Typification Project, launched in 1981 at the London Natural History Museum to match Linnaeus's thousands of designations with the specimens and illustrations in his work. Jarvis's book chronicles this project and presents nearly 700 pages of names and their types - from Abrus precatorius L. to Zygophyllum spinosum L. Jarvis and his colleagues scoured museums and private collections to create this wonderful

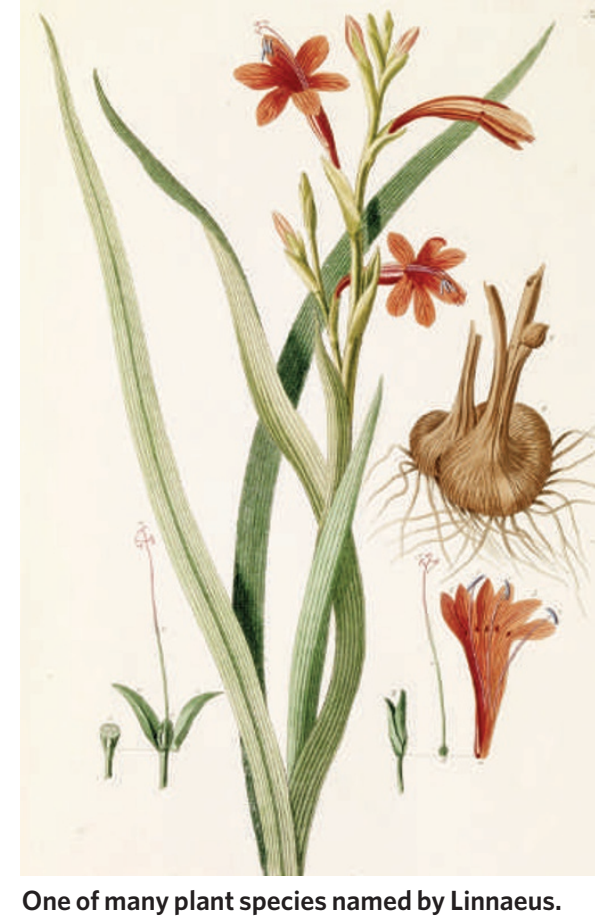

One of many plant species named by Linnaeus. reference for all those involved in taxonomy.

The book is a work of art. Even non-botanists will be seduced by this inviting package. The text is peppered with photographs and illustrations of spectacular examples of plant diversity and linnaean memorabilia. Figures range from a photograph of Linnaeus's signature and seal from 1734 , to an illustration of the wild woodland twinflower (Linnaea borealis), to Georg Dionysius Ehret's (1736) illustration of Linnaeus's 'Sexual System' of plant classification.

The appreciation for history in plant systematics is evident in this book and in the attention being paid to Linnaeus during 2007 . Even the controversy between those who favour the continued use of linnaean classification and advocates of the PhyloCode (the system that relies on evolutionary history) does not diminish Linnaeus's contribution. This book is a timely homage to linnaean names and the efforts of Jarvis's team, as systematists look for new ways to provide the richest classification systems. Pamela S. Soltis is at the Florida Museum of Natural History, University of Florida, Gainesville, Florida 32611, USA.

\title{
The theatre of quantum physics
}

\section{Faust in Copenhagen: A Struggle for the Soul of Physics by Gino Segrè \\ Viking/Jonathan Cape: 2007. 320 pp. $\$ 25.95 / £ 20.00$}

\section{Finn Aaserud}

The year 1932 was a particularly eventful one in physics. In Faust in Copenhagen, the physicist Gino Segrè chooses as his point of departure an annual meeting held in April of that year at Niels Bohr's Institute for Theoretical Physics at the University of Copenhagen, Denmark. In Segrè's view, the 1932 gathering symbolized the end of the political neutrality of physics and physicists, coinciding as it did with the arrival of Hitler and crucial discoveries in nuclear physics that would make possible the subsequent development of the atomic bomb.

Segrè introduces us at the outset to seven physicists who attended this series of informal but prestigious meetings: Niels Bohr, Paul Dirac, Werner Heisenberg, Paul Ehrenfest, Max Delbrück, Lise Meitner and Wolfgang Pauli. He presents a fascinating comparison of these main characters in the first hundred pages, and then launches into a spirited and engaging history of the development of quantum physics from about 1900 to 1932. Segrès emphasis is always on the human aspect, and he is unable in this part of the book to limit his story to the seven physicists whom he claims the book is about. Towards the end, he returns to the original group, vividly describing their subsequent careers, again with illuminating comparisons. As the nephew of Emilio Segrè, a Nobel prize-winning physicist trained by some of the main characters in the book, Segrè deploys his background effectively for dramatic and comparative purposes. This, however, shortens his distance from the subject matter - for example, the role of experimental physics at Bohr's institute is underplayed. Moreover, he seemingly contradicts his interpretation of the 1932 meeting as the end of the political neutrality of physics, by praising his own field for continuing to this day in the disinterested tradition instigated by Bohr.

Bohr's crucial contributions to quantum mechanics, Segrè writes, were "largely ignored" by Segrès own generation of physicists, and he seems intent on rectifying the situation. Whether or not this is necessary, Segrè's approach reveals important insight into Bohr as a person as well as into his interaction with and importance for physicists who followed him.

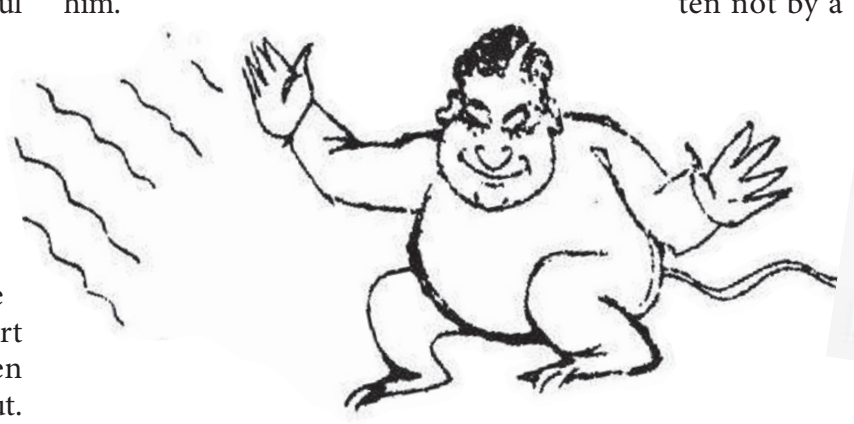

At the end of the 1932 meeting, in celebration of the hundredth anniversary of Johann Wolfgang von Goethe's death, some of the younger scientists performed a parody of Faust, replacing Goethe's original characters with some of the main theoretical physicists of the day, most of whom were also assembled in Copenhagen: Niels Bohr was portrayed as God, Wolfgang Pauli as the Devil and Paul Ehrenfest as Faust. The parody described the state of physics at the time, and Segrè regards it as sufficiently important to name his book after it.

At least to me, however, Segrè does not integrate the play into his narrative satisfactorily. The worldwide success of Michael Frayn's play Copenhagen, first set up in London in 1998, inspired a still-active interest in the relationship between science and the theatre. Frayn's play even shares two of Segrès main characters - Niels Bohr and Werner Heisenberg. But Faust as enacted at the 1932 meeting was written not by a

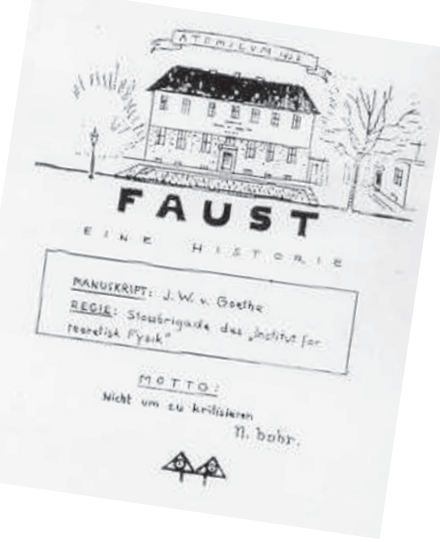

Wolfgang Pauli as the Devil in a parody of Faust, performed by physicists at a meeting in 1932. 
professional playwright but by the participant physicists themselves, and one might have hoped that Segrè would have used the opportunity to offer a new twist to the relationship in question. Admittedly, there are quotations from the original Faust at the head of each chapter, as well as a chapter entitled 'Goethe and Faust' and another comparing the physicists' play with Goethe's original. But these instances are provided largely in isolation from the main narrative of the book.

In 1932, German was still the main language of physics - and culture - so the choice of Goethe's Faust as a basis for a satire enacted in German seems natural. Probably in anticipation of his likely readership, Segrè does not quote from the original German, but quotes instead from necessarily inferior English translations. The many quotations from Goethe's Faust are taken from Anna Swanwick's excellent, but by now somewhat archaic, translation from late in the nineteenth century. Likewise, Segrès treatment of the physicists' Faust is based on the spirited, but sometimes inaccu- rate, English translation published in 1966 in a highly personal account, Thirty Years That Shook Physics, by the physicist George Gamow (to whom Segrè dedicates his book).

The photographs used to illustrate Faust in Copenhagen are well chosen. Apart from a few minor omissions and factual errors, the book is lively and readable and provides an exciting impression of the development of theoretical physics during a crucial period.

Finn Aaserud is director of the Niels Bohr Archive, Blegdamsvej 17, DK-2100 Copenhagen, Denmark.

\section{Medical history without frontiers}

\section{Medieval Islamic Medicine \\ by Peter Pormann and Emilie Savage- Smith \\ Georgetown University Press/Edinburgh \\ University Press: 2007. 223/256 pp. \\ $\$ 29.95 / € 18.99$}

\section{Yasmin Khan}

What is 'Islamic medicine'? It is a term fraught with limitations. No definitive definition exists, but most reputable historians of medicine have characterized it by several key features. These include a chronological marker that spans a medieval period of a thousand years and encompasses specific but vast geographical regions from Spain and North Africa in the west, to central Asia and India in the east. Its successes were inspired implicitly by the Islamic faith, but sometimes involved discreet collaboration of Muslims with non-Muslims, who used Arabic as the lingua franca to cultivate the resulting phenomenon.

These idiosyncratic dynamics of Islamic medicine are explored in Medieval Islamic Medicine. With their meticulous research on newly translated manuscripts, two pre-eminent scholars of medical history, Pormann and Savage-Smith, have revisited the topic discussed in the classic text Islamic Medicine by Manfred Ullmann, published almost 30 years ago.

Their new, brief overview is destined to become a definitive entry-level textbook, owing in part to its simple structure, comprehensive analysis and succinct interpretation of key historical figures and their achievements. It relies on a thematic rather than chronological approach, which enhances its readability.

The book discusses the emergence of medieval Islamic medicine and the subsequent crosspollination with medicine in other cultures. We are given a sense of how Muslims perceived the body as well as the soul as precious, because it was derived from and accountable to God as the creator. The body therefore required constant and dutiful care, and had the right to be maintained and preserved and protected from abuse, meaning that the individual was bound to seek a cure for any ills. These sensibilities were influenced by precursor civilizations particularly ancient Greece - and reinforced by the Islamic faith.

Pormann and Savage-Smith refute the clichéd view that the Islamic medieval civilization was merely a bridge between ancient and modern medicine. They show how Muslims built on Greek knowledge, in addition to preserving and translating it. The resulting new ideas and theories later percolated further into the West through translation, trade and travel, as well as

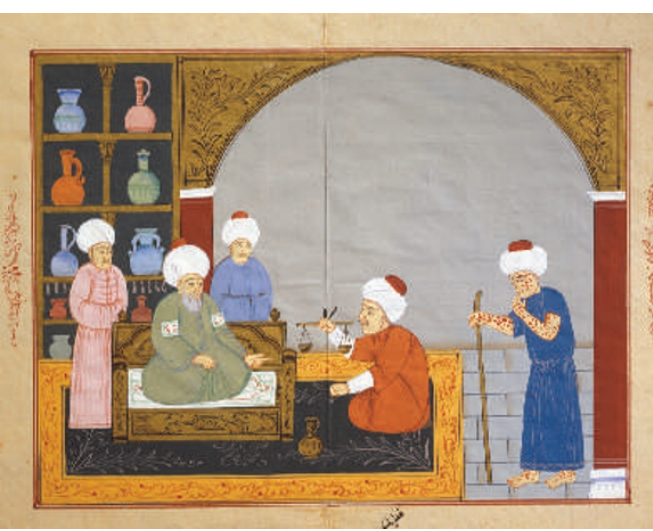

A Persian physician gives instructions for preparing smallpox remedies in the eleventh century.

during the crusades, acting as a springboard towards the European renaissance and thus forming the roots of modern medicine.

The book emphasizes the inclination of early Muslim medical practitioners towards Unani Tibb, a form of Islamic medical tradition stemming from early Greek medicine. This involved balancing, through diet and medicinal herbs, the four humours - air, earth, fire and water, which correspond to the four bodily fluids blood, phlegm, black bile and yellow bile - and understanding that a good environment and spiritual peace are essential for good health. Today such a holistic approach to well-being, although experiencing a resurgence, is outside mainstream modern medicine.

The authors avoid the irksome cumulative and linear approach that besets many texts and museum displays of medical history, which often portray the past as inferior and the present as the benchmark of progress. And without taking the 'great man of history' line, they give us Islamic medical pioneers aplenty - for example, Abu al-Qasim al-Zahrawi (Albucasis). This accomplished surgeon from eleventh-century Muslim Spain first described and used forceps for extracting fetuses during stillbirths, developed other specialized surgical tools, and sutured wounds using cat gut.

Pormann and Savage-Smith also discuss the role of women in the development of medieval Islamic healthcare. Patronage by wealthy women associated with those in power proved instrumental in providing the financial investment needed for establishing hospitals in Baghdad from the ninth century. These institutions offered free, specialized treatments, which resembled the founding ethos of the modern British National Health Service.

What led to the demise of the stronghold of Islamic medicine in general is not addressed in the book: this is an unresolved and complex question. Some blame religion, or the lack of it, and others point the finger at social factors such as war and colonialism. This subsidence has been perpetuated and exacerbated by the 'brain drain' phenomenon. That said, the legacy created by the practice of Islamic medicine is alive and thriving in the rural Middle East, throughout Africa, among the Muslims of southern Asia and in Asian diaspora communities in Europe and the United States, indicating that there is scope for a wider revival.

Medieval Islamic Medicine is a measured and scholarly book that is a timely rebuke to those tempted to dismiss the past as irrelevant. The medieval period when the Islamic world drove medical development and discovery is an indication that Islam itself is not inimical to progress. This book should be read by anyone interested in the real story of civilization. It is a notable contribution to the promotion of a multicultural public understanding of the history of science.

Yasmin Khan is exhibition coordinator at the Science Museum, Exhibition Road, London SW7 2DD, UK. 